\title{
Extending the Enterprise: An Evaluation of ERP and EAI Technologies within a Case Study Organisation
}

\author{
Amir M. Sharif and Zahir Irani \\ Brunel University, \\ School of Information Systems, Computing and Mathematics, Uxbrdige, \\ Middlesex, UB8 3PH, \\ \{ams@amir.demon.co.uk, zahir.irani@brunel.ac.uk\}, \\ WWW home page: http://www.brunel.ac.uk/ csstzni
}

\begin{abstract}
It is widely understood that both Information Technology (IT) and Information Systems (IS), provide great benefits in improving the visibility of supply and value chains within and across organisational boundaries. Those enterprises which can realise the benefits of extending their core business processes outwards to clients and trading partners, will be able to create unique supply chain-dependent products and solutions. Thus, such business infrastructures have enabled organisations to expand and improve the effectiveness of their enterprise. One method to achieve this, has been to integrate Enterprise Resource Planning (ERP) systems with web-based and other IS systems, using Enterprise Application Integration (EAI) technologies. This paper seeks to investigate those factors which contributed to a case organisation's extended enterprise experiences, by using extant ERP and EAI implementation IS evaluation criteria; and by placing the research results within the context of applicable IS research techniques in the area.
\end{abstract}

\section{Introduction}

Much of the benefits attributed towards adopting Information Technology (IT) and Information Systems (IS), centre on the ability to speed up decision-making, improve process productivity and efficiencies and increase the level of control available to management. The joint effects of market globalization and competition that is ever more sophisticated is urging producers, distributors and vendors to integrate their operations, in order to maintain competitive advantage. Companies that are successful with Supply Chain Management (SCM) increasingly have to compete on their ability to work rapidly with customers and trading partners (Boyson et al. [1]);

Please use the following format when citing this chapter:

Sharif, A., M., Irani, Z., 2006, in International Federation for Information Processing, Volume 205, Rescarch and Practical Issues of Enterprise Information Systems, eds. Tjoa, A.M., Xu, L., Chaudhry, S., (Boston:Springer), pp.383-395. 
as we; as optimizing the interface between IT/IS and humans (Willcocks and Sykes [2]), in order extend the reach of the organization towards becoming a "Digital Enterprise" (Tapscott et al. [3])

This paper seeks to assess and analyse how technological and organisational factors occur within the context of an extended enterprise context. By using data from a case study organisation, the authors focus on both system as well as process behaviours. As is well known and understood within the qualitative information systems research community, the application of a case study context provides the researcher with access to a protocol and coding methods which allow feature-rich behavioural, organisational and process-related data to be harnessed and gathered (Orlikowski and Baroudi [4], Walsham [5] and Yin [6]). By assessing the case organisation's attempts at implementing an extended enterprise approach, the authors seek identify key factors for carrying out research in this area of MIS.

\section{Research Approach}

The rationale behind this research was to investigate and highlight those technological and organisational aspects of implementing an extended enterprise, by carrying out a case study analysis on an organization embarking upon such a project. The authors now define the research approach employed in terms of the background, data and focal theory relating to the topic.

\subsection{Background Theory: the Extended Enterprise}

The concept of an extended enterprise is congruent with the idea of a Virtual Organisation. As such, the underlying notion is that of a business entity which exists as a so-called "borderless" form, having access to people, process and technological resources which may or may not be rooted in physical, i.e. geographical space (Goldman et al. [7]). Hence an extended enterprise can be said to comprise of three aspects: a set of extended business relationships across and between an organisation's customers and suppliers (Malone et al. [8]); a business ecosystem which belies a set of business processes (Tapscott et al [3]), which is underpinned by a networked supply chain, which require the integration of inter-organisational systems (IOS). Hence, the authors suggest that the fundamental components of extended enterprises rely heavily upon both Enterprise Resource Planning (ERP) and Enterprise Application Integration (EAI) technologies (Linthicum [9]).

Figure 1 shows a model of these facets. This highlights business-to-business / business-consumber (B2B / B2C) architectures, which provide communication and automation of business processes across and between enterprises (Daniel and Klimmis [10]); Digital Marketplaces (DMP) which are a collection of B2B vertical/horizontal supply chain intermediaries (Strader and Shaw [11]); and ERPII, which is an externalisation of an organisation's SCM, Customer Relationship Management (CRM) and ERP functionalities (Bakht [12]). 


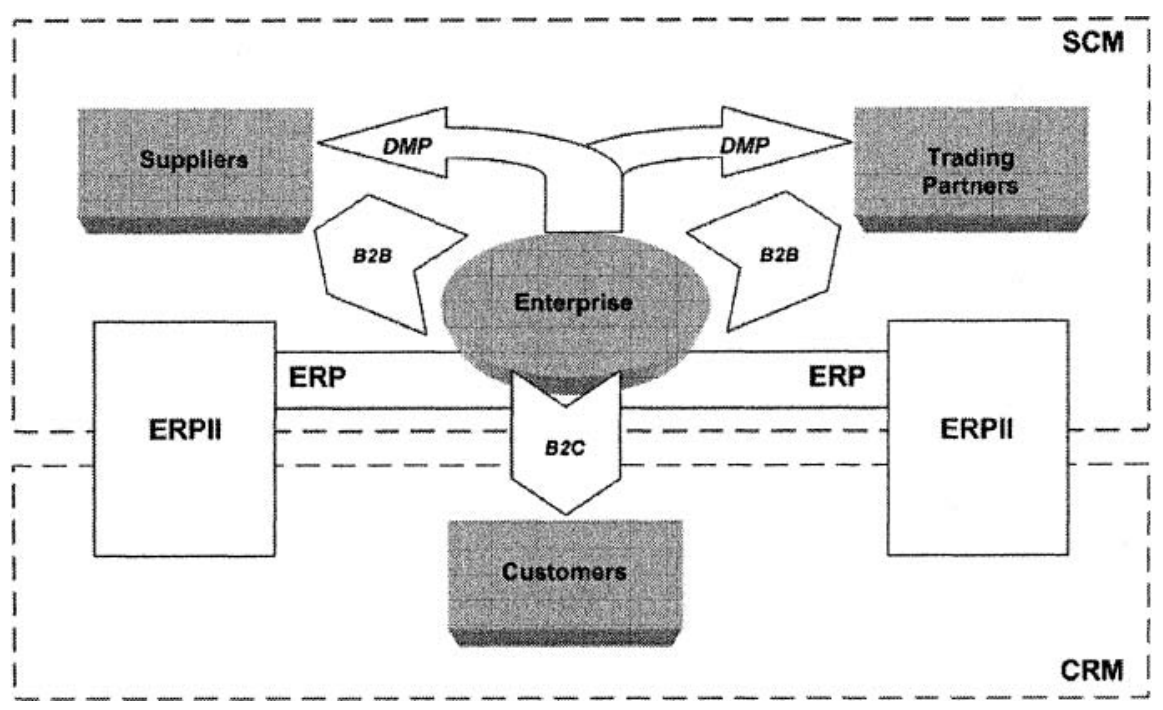

Fig.1 A model of Extended Enterprise components

\subsection{Data Theory}

The authors are primarily concerned with analyzing human factors in relation to organizational systems, in terms of an empirical case study approach, where the primary units of analysis will be via narrative discourse and discussion. The authors believe this can be achieved by applying a range of ERP and EAI evaluation criteria: 4 business-based (actor) models from the ERP literature (Akkermans and van Helden [13]; Dalal et al. [14]; Lee et al. [15]; Swanson [16]); and 7 technology-based (network) models from both the ERP and EAI literature (Al-Mudimighi et al. [17]; Brehm et al. [18]; Linthicum [9]; Parr and Shanks [19]; Schmidt [20]; Themistocleous et al. [21]; Themistocleous [22]). This is in the vein of the taxonomical approach to Information Systems Evaluation as defined by Irani and Love [23] and in the importance that should be given to identifying those emergent aspects of supply chain management as highlighted by Sherif et al. [24]. Hence, the research methodologies employed within the extant MIS literature on this subject, tend to focus on and support the integrative nature of the impact of technology upon people and processes. In so doing the authors seek to not only analyse the case company's experiences in the light of evaluative models but thenceforth compare and extract those details from the case company, which can aid the MIS researcher in investigating this field further. This will be achieved by a brief comparison of this data via the lens of organizational, socio-technical and systems theory components. 


\subsection{Focal Theory}

The theoretical stance taken by the authors in this paper, is that of providing a view into the richness of the exogenous / endogenous relationship of humans and the systems they interact with. This is achieved through using a socio-technical lens, in the guise of the application of Actor-Network Theory (Tatnall and Gilding [25]). This is in order to relate the (albeit loose) network of heterogeneous sociological and technical actors within the given extended enterprise context. This context of social factors within the IS setting, is as favoured by and noted by Orlikowski and Baroudi [4], Lamb and Kling [26], and Nichols [27] - all who suggest using multiple modes of analysis within complex organizational settings. As Rose [28] notes, the advent of this particular lens allows for a more convenient operationalisation of the concept of Giddens' "structural agency" (Structuration), making the relationships between agents and the context within which they exist, based upon an interpretivist epistemology.

The underlying research method used is that of the case study type (Yin [6]) following an Empirical, Interpretivist philosophy (Klein and Myers, [29]). The data collection procedure followed all the major prescriptions within the literature for doing fieldwork research (Walsham [5]; Yin [6]; Fiedler [30]). This was applied within the overall context of the normative Information Systems Evaluation (ISE) literature, which suggests that the primary reason why organisations fail to realise benefits from their IT/IS investments lies with a lack of understanding with regards to the evaluation of human, organisational and technology perspectives (Irani and Love [23]). The authors sought to gather primary data (via a semi-structured interview and participant observation protocol) and secondary data (via organisational reports, memos and archived material). One on one interviews and discussions were conducted with the Chief Executive Officer (CEO), Chief Operating Officer (COO), Chief Technology Officer (CTO) and Chief Financial Officer (CFO), as well as two managers from the IS department. This interviewing technique was carried out in the manner of that proposed by Tan and Hunter [31], using 'probe' questions as suggested by Shaughnessy and Zechmeister [32]: i.e. an extended interview where responses were fed back to the interviewee, allowing for the resolution of research biases from the interviewer. Numerous secondary data sources were also used, such as internal reports, budget reports, archived documentation and filed accounts that were later transcribed. The findings are subsequently presented using a narrative mode of analysis, which has over the years become popular within the field of IS (Orlikowski and Baroudi [4]; Walsham [5]). Hence, given this contextual background, the case detail is now presented.

\section{Case Detail}

The case company investigated is an internationally renowned Global industrial products company (herein known as Company $\mathrm{X}$ ), specialising in industrial control, workshop scheduling, safety, control systems and software. Company $\mathrm{X}$ boasts a 
range of global clients and suppliers across manufacturing, pharmaceuticals, process automation, computer software / hardware and systems integration. At the time of conducting the research, Company $\mathrm{X}$ had approximately 15 IS product lines feeding into production planning and fulfilment processes, involving a tight integration with core ERP. Senior management realised, that if by integrating information across and within their industrial automation software product line, via a core ERP package, potentially both suppliers as well customers could be able to see the state of the order, build, design, forecast, production and control cycles more easily. Hence, an extended enterprise. For trading partners of the case organisation (resellers and external strategic alliance partners) sales level information would be required to be shared and seen. This would encompass sales contact, product and support / maintenance information. Customers of Company $X$ would also be able to access and demand a range of services, products and information via so-called "shopping cart" functionality; sales order and shipping information; and on-line help. Management instigated an EAI programme to enhance the integration between the organisation's order entry, planning, production and order tracking and logistics technologies. Under the auspices of the CEO and board, the project would involve the delivery of an internal "B2B portal" concept. This would be carried out using Baan as the core manufacturing process ERP system in order to aggregate planning and fulfilment information for customer orders, in effect embracing both partners and customers (as shown by Davis [33]). Thus, by integrating both core CRM, ERP and SCM components of their enterprise, both manufacturing and shipping operations can be combined in a single manner (i.e. once again, in an ERPII sense). Although Company $\mathrm{X}$ had enthusiastically highlighted and began working on this initiative, it did not fully realise the effort that was involved.

From the outset and as a result of an internal IT audit, the organisation unwittingly faced the prospect of upgrading and maintaining its current SAP R/3 product internally, which was nearing its license re-purchase state, and was therefore looking to be a significant cost outlay. Crucially, Company $\mathrm{X}$ decided to adopt Baan not only as their own internal core ERP, but also as the basis of their software products also. This was because the module architecture fitted its discrete manufacturing processes better. As such, senior management persisted in making a switch to Baan ERP, given its stated aims at the behest of the managing director. The apparent disregard for the inherent risks associated with moving away from core SAP ERP and the vigorous and aggressive timescales suggested by senior management, did not take into account the change management issues which would be encountered.

For all company admissions about involving stakeholders, partners and even external systems integrators, the reality of executing the project plan meant that Company $\mathrm{X}$ effectively ignored such external involvement (as can be seen in the project plan itself). Thus, considerable effort had to be expended in order to integrate and consolidate the core business process applications (not least of which, was replacing their existing ERP package, SAP, with Baan). As an ensemble effort, the application development and rollout of the system was scheduled to be delivered within an aggressive timeframe of 12 months. The initial scoping and definition of 
the integration effort required, took 6 man months alone to complete. Such estimates were driven and mandated by senior management, with a disregard for the active and necessary involvement of technical and operational IT/IS managers within the divisions concerned. The Chief Financial Officer (CFO) also commented that unless costs were also not tightly controlled, such a strategic project could easily come off the rails. As such, the proposed B2B portal concept and EAI implementation was shelved after a period of 6 months as it became clear, that the successful adoption of Baan internally in order to achieve "reference site" status, was not achievable. Also, product line heads (such as for Enterprise Management and Automation) were also concerned about the extent of effort required in order to integrate and standardise their product lines with Baan (which had not even been fully implemented as a core ERP within the company). Company $X$ therefore was left with the task of continuing with attempting to replace its SAP ERP with Baan ERP - focussing all its efforts on completing an ERP as opposed to ERP-EAI integration programme (ultimately returning back to utilising its core abilities). In summary, their experiences were as follows:

- Little understanding of the level of complexity involved in replacing SAP with Baan;

- Change management / process re-organisation, not understood by management;

- Difficulty in managing both the operational business and the strategic initiative at the same time.

\section{Case Analysis}

In order to understand the case organisation's experiences, the authors now apply evaluation models from the ERP and EAI research literature in order to ask: can we learn anything more by applying the evaluation models?; and can we identify any aspects which can assist in forming a research agenda in the field?

\subsection{Evaluation of the Extended Enterprise implementation}

The selection and approach of the given literature-based methods attempted to balance both those organisational with technical factors in order to draw conclusions from the symbiotic nature of man and system in this regard. The results are shown in Table 1 and are now discussed in further detail.

In terms of "old economy" processes, it is immediately clear that models T.g and O.a (ERP tailorability and pre-modelling) were not apparent at all, and that the B2B portal platform was not going to be considered for low transactional liquidity. Conversely, it appears that there was greater concentration around models T.a, T.b, T.f, O.b and O.d (EAI process steps, EAI interconnections, ERP implementation approach, Organisational impact of enterprise integration ERP implementations and 
IS innovation level, respectively). This was in terms of technology considerations; whilst in terms of business (and hence actor) components, there was an emphasis on planning and control, internal focus, and limited user involvement. Overall there appears to have been a general concentration around procedural capabilities, and hence existing skills and experience (although the slightly below average result of model T.d belies a lack of deep integration skill).

The view of the organisation's ERP implementation lifecycle, was short to medium term, and as defined by model T.e, the implementation path taken was strategic only (not operational or tactical), the focus being on finding a rapid solution without much thought for the practicalities of the implementation. At the same time however, the organisation was attempting to go beyond this level of capability in terms of embracing and capturing the spirit of "new economy" tools, technologies and paradigms. Here it can be seen that there was a general lack of understanding and recognition of an ERP implementation approach (model I.f), and gravity of the number of EAI interconnections required (model T.b). This further highlights the lack of understanding given to the impact of the ERP system (O.b). For all company $X$ 's views and ideals on creating a borderless, connected enterprise network with its supplies, partners and customers, the breadth and depth of its business processes was also negated by their implementation approach also.

As noted, there was little user involvement and appreciation of a multi-dimensional (or rather, multi-contextual) view of the plan-source-make-move lifecycle envisioned by the firm. Furthermore, concepts of agility, flexibility and high transaction liquidity although mandated, were not evident in the design and implementation of the B2B portal. Hence as can be seen there was a greater desire to concentrate on those technology aspects of ERP tailorability and enterprise modelling (model T.g and O.a, respectively), but this could not be realised due to a lack of thoroughness in models T.b, I.f and O.b (EAI interconnections, ERP implementation approach and Organisational impact of enterprise integration ERP implementations, respectively). Company $\mathrm{X}$ faced / instigated a dichotomy in how it viewed its business processes. Again this emphasises the fact that due to limited user and stakeholder involvement in the implementation of the given B2B portal, and an over-reliance on using existing technologies, the goals of achieving the whole business perspective, customer-centric organisation were never fully realised (although, as we know, they were articulated as such by senior management).

So it could be said that strategic goals were trying to be achieved at the expense of tactical and operational considerations. Likewise, in network (technology) terms, there was a preference/desire to address the tailorability of the new ERP (SAP) alongside attempting to be innovative and design the processes around the system (models T.g, O.d and O.a respectively). At the other end of the scale, it can be seen that there was less reliance and importance given to the ERP implementation approach to be used (model I.f), along with the organisational impact of the given system (model O.b) and finally the level of adoption of the resulting implementation (model T.c). 
Table 1. Analysis of integration approach, using ERP and EAI evaluation models

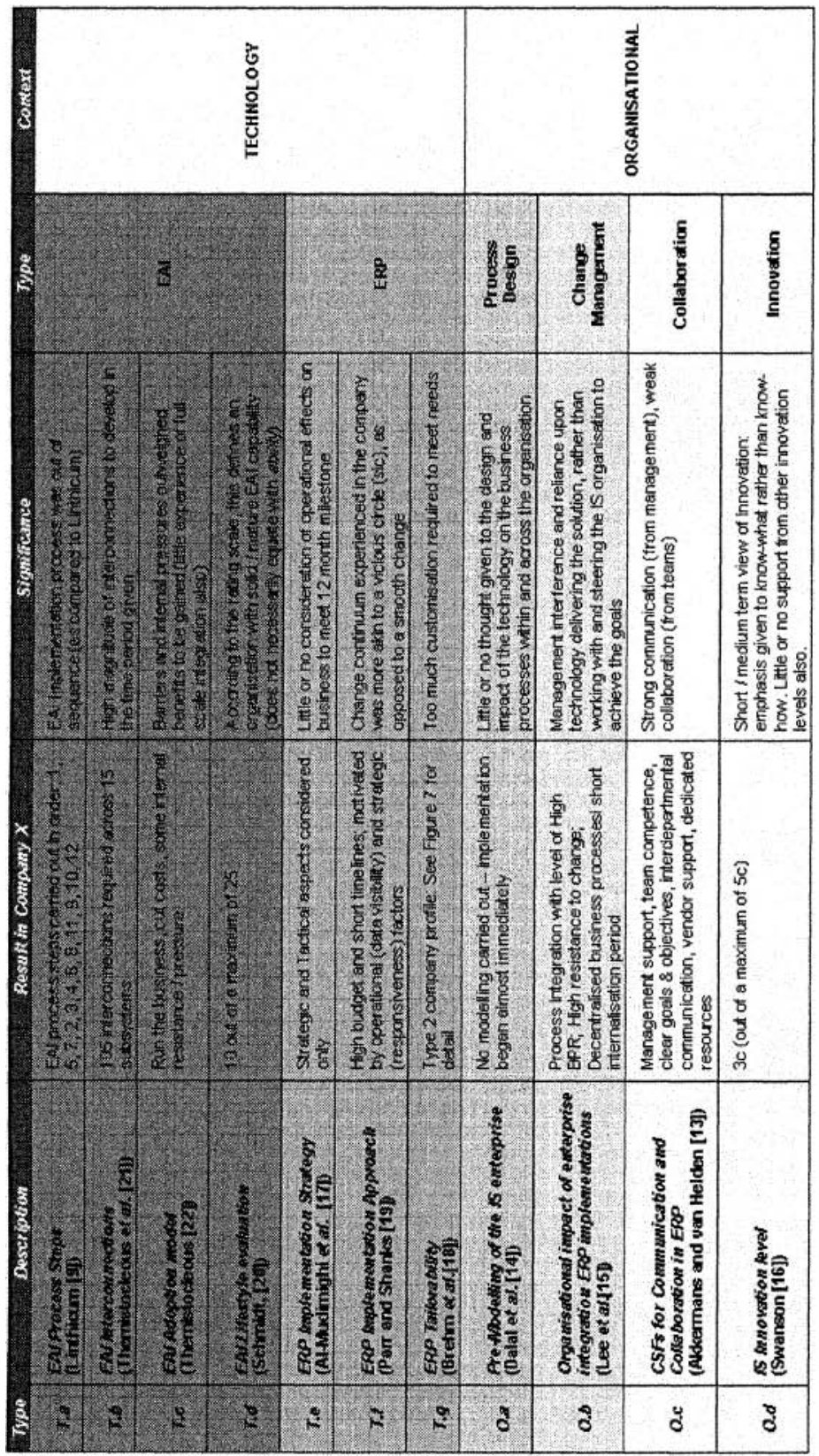


Model O.c shows that there was strong communication but weak collaboration. Again, as similar to the result of model T.g, only a handful or project success characteristics were applied, at the expense of others which were not immediately evident. So in the case of Company $\mathrm{X}$, although factors relating to management control, communication and overall support for the programme were evident, it is important to highlight those CSFs which were not found, such as: interdependent cooperation; management of expectations; existence of a project champion; careful package selection; user training; education on new business processes; business process re-engineering; choice of a technical architecture; change management; and the use of consultants (and other professional services). In short, Company $\mathrm{X}$ decided to "go it alone" on this initiative, and as a result, it took on a large effort in technical and organisational change which could not be sustained with the resources it had in place. Coupled with the high level of management interference (as shown in model $\mathrm{O} . \mathrm{b}$ ), there was a great amount of communication from senior and middle management, but little collaboration amongst the individual software divisions that had to integrate their systems together. This was also exacerbated by the lack of a cohesive group business structure to facilitate effective collaboration and discussion (as highlighted earlier). This led to what Akkerman and Van Helden describe as a vicious circle: poor communication, begetting poor collaboration, leading to a "spiral" of failure. Therefore, there was little understanding of the impact on the firm's people and how the step-change in technology would affect their processes.

\subsection{Researching the extended enterprise: a synthesis}

Company X tried to employ an internal B2B type architecture, in order to realise the goal of an extended enterprise. In other words, it attempted to implement a combined approach to extend and integrate a base-level ERP system to encompass CRM and SCM functionalities, through an application integration approach: hence ERPII. Indeed, the vague and wanton usage of the term B2B by Company X as relates to this specific integration programme, was something of a misnomer as there was no external integration carried out during this phase. This was purely an internal EAI scheme (i.e. intra-enterprise application integration), but couched by management in the terms and language of contemporary business information systems terminology. Although this might have been, as Dixon and John [34] state, a synergistic affect of articulating IT needs, this confused the technical issues around the exact needs and requirements of the integration to be achieved. Because it was trying to extend the capabilities of the underlying Baan ERP, Company $\mathrm{X}$ was unwittingly involved in attempting to carry out an ERPII-type implementation: but using traditional ERP and EAI techniques to do so.

Furthermore, the case study analysis has highlighted several necessary precedents for enacting an extending enterprise initiative, in the application of an ERP/EAI evaluative lens. It is quite clear that there was a distinct lack of planning involved; a lack of consultation with intended supply chain stakeholders being impacted (suppliers, trading and alliance partners); there was no supporting collaborative effort 
to get cross-divisional software teams and groups to actively approach the integration effort together; the company was effectively attempting to address internal integration issues - but not providing or planning for a complete B2B solution (between itself, its suppliers, partners and vendors); and a high degree of complacency in terms of Company $\mathrm{X}$ underestimating its technical capability in an area in which it had little or no experience, of replacing its existing ERP system (i.e. SAP for Baan). In short, there was a lack of cohesiveness in bringing together resource complementarities (collaborative opportunities and processes), org design (decentralisation with re-integration), ent IS, relationship management (governance, contracts and incentivisation) and sustained competitive advantage (IT as a valued resource). Hence, it can be concluded that achieving an extended enterprise is a difficult and complex exercise and requires at the most fundamental level, a consistent commitment to stated goals and objectives of an underlying, disintermediating, yet flexible business model across supply chain stakeholders. The linkage between this strategic and operational view of the firm as noted by Constantinides [35] is hence critical to extended enterprise success.

Whilst the case study methodology applied in this paper did reveal and highlight significant technological failings, the results of the evaluation show that there was an inherent human aspect of the programme undertaken. This therefore highlights the usefulness and appropriateness of the case study approach employed, similar to that reported by Kumar and Crook [36] who suggest that empirical analysis of such organisational contexts, allows for the identification of inter-organisational conflicts. The relevance and understanding of all aspects of supply chain management, from sales order fulfilment right through to third and fourth-party logistics, is becoming increasingly important for MIS researchers and practitioners. The authors also believe that a continuing development of inter-disciplinary knowledge transfer, is vital to extending the debate and discussion of such disintermediating technologies and concepts as the Extended Enterprise. As the cursory survey of the literature in Table 1 shows, there is a wide spectrum of research techniques that cover all aspects of this area. Hence the study of extended enterprises themselves should tend towards a multidisciplinary approach to capture such facets, as Chiasson and Davidson [37] as well as Sherif et al. [24], note in using IT artefacts and resource complementarities within a socio-technical context.

Hence in order to address and realise the nature of such a business strategy as the extended enterprise, the authors suggest viewing the continuum of issues as reported in the given case study, in terms of a multidisciplinary approach. Indeed, as the results in Table 2 show, the application of a technology prototyping or enterprise model would have been useful in order to emote and elucidate the implementation aspects of such a strategy (as has been noted by Lin et al. [38]). Furthermore, although the case study approach taken by the authors within this article has sought to capture a sense of the impact of such an initiative, the wider implications of management behaviours and organisational actions, needs to be placed within a longitudinal context. This could likewise be achieved by extending the period or scope of study outwards across all supply chain participants, employing an even deeper level of analysis. This in-depth evaluation of supply chain participants could 
possibly be achieved by applying a hybridisation of a case study and action research, via a socio-technical lens, in order to relate supply chain people, processes and technology factors together.

\section{Conclusions}

This paper has outlined and discussed how an industrial automation company, attempted to transform itself into an Extended Enterprise, through the introduction of a combined ERP and EAI approach. The authors applied a number of ERP/EAI evaluation models in order to highlight the approach taken by the organisation, in the context of a socio-technical stance (considering both human and systematic facets). Thus, it was found that an extended enterprise implementation requires a holistic approach to People, Process and Technology (in terms of supply chain participants; value chain integration; and ERP/EAI implementation). The authors suggest that future research in the area of extended enterprises / virtual organisations, within the context of implementing IT/IS, should attempt to uncover such facets, possibly via applying a hybrid approach to uncovering both socio-technical and institutional factors, as outlined in terms of the extant literature in Table 1. Indeed this requires knowledge an insight from experts across a number of connected fields (sociologists, MIS, supply chain included), using an empirical and qualitative lens, within a longitudinal timeframe. Hence, the authors also agree with Rose [28] in that a combined approach of Actor-Network Theory with the operationalisation of structural agency theory (Structuration) may help to provide a deeper insight into the thetic and antithetic aspects of inter-organisational systems, and their related processes. In doing so one can gain a better understanding of this emerging field and its boundaries.

\section{References}

1. S. Boyson, T.M. Corsi., M.E. Dresner, L.H. Harrington, and E. Rabinovich, Logistics and the Extended Enterprise (John Wiley and Sons, New York, 1999).

2. L.P. Willcocks, and R. Sykes, The Role of the IT Function, Communications of the ACM 43 (4), 32-38 (2000).

3. D. Tapscott, G. Ticoll, and F. Lowy, Digital Capital (Harvard Business School Press, Boston, Massachusetts, 2000).

4. W.J. Orlikowski and J.J. Baroudi, Studying Information Technology in Organizations: Research Approaches and Assumptions, Information Systems Research 2, 1-28 (1991).

5. G. Walsham, Interpreting Information Systems in Organisations (John Wiley and Sons, New York, 1993).

6. R.K. Yin, Case Study Research: Design and Methods - 2nd Edition (Sage Publications, Thousand Oaks, California, 1994).

7. S.L. Goldman, R.N. Nagel, and K. Preiss, Agile Competitors and Virtual Organizations, Strategies for Enriching the Customer (Von Nostrand Reinhold, New York, 1995). 
8. T. Malone, J. Yates, and R. Benjamin, Electronic markets and electronic hierarchies, Communications of the ACM 30 (6), 484-497(1987).

9. D. Linthicum, Enterprise Application Integration (Addison-Wesley, Massachusetts, 1999). 10.E.M. Daniel, and G.M. Klimmis, The impact of electronic commerce on market structure: an evaluation of the electronic market hypothesis, European Management Journal 17(3), 318 325 (1999).

11.T.J. Strader, and M.J. Shaw, Characteristics of Electronic markets. Decision Support Systems 21(3), 185-198 (1997).

12. A. Bakht, Get ready for ERP, Part II. Available. on-line. http://www.tribuneindia.com/2003/20031201/login/guest.htm. December 1st, 2003.

13. H. Akkermans and K. van Helden, Vicious and Virtuous Cycles in ERP Implementation: A Case Study of Interrelations between Critical Success Factors, European Journal of Operational Research 11, 35-46 (2002).

14. N. Dalal, M, Kamath, W. Kolarik, and E. Sivaraman, Toward an integrated framework for modeling enterprise processes, Communications of the ACM, 47(3), 83-87 (2004).

15. J. Lee, K. Siau, and S. Hong, Enterprise Integration with ERP and EAI, Communications of the $A C M$ 46(2), 54-60 (2003).

16.E.B. Swanson, Information Systems Innovation among Organizations, Management Science 40(9), 1069-1092 (1994).

17.A. Al-Mudimigh, M. Zairi, and M. Al-Mashari, ERP software implementation: an integrative framework, European Journal of Information Systems, 10(4), 216-226 (1994).

18. L. Brehm, A. Heinzl, and M.L. Markus, Tailoring ERP Systems: a spectrum of choices and their implications, in: Proceedings of the 34th Hawaii International Conference on Information Systems (HICSS'34), January 3rd - 6th 2001, Maui, Hawaii, USA, edited W.R. Sprague III (IEEE Computer Society, New Jersey, 2001), pp.8017-8026.

19.A.N. Parr and G. Shanks, G, A Taxonomy of ERP implementation approaches., in: Proceedings of 33rd Hawaii International Conference on Systems Sciences (HICSS), January 4 th -7 th 2002 , Hawaii, USA, edited by W.R. Sprague III (IEEE Computer Society, New Jersey, 2002), pp. 2424-2433.

20. J. Schmidt, EAI Lifestyle Evaluation, EAI Journal April, 64 (2003).

21.M. Themistocleous, M., Z. Irani, and A.M. Sharif, Evaluating Application Integration, in: Proceedings of the 7th European Conference on IT Evaluation (ECITE 2000), Trinity College, Dublin, Ireland, September $28-29$ th 2000 , edited by A. Brown and D. Remenyi (Academic Conferences, Reading, UK, 2000), pp. 193-202.

22.M. Themistocleous, Justifying the Decisions for EAI Implementations, Journal of Enterprise Information Management 17(2), 85-104 (2004).

23.Z. Irani, and P.E.D. Love, The Propagation of Technology Management Taxonomies for Evaluating Information Systems, Journal of Management Information Systems 17(3), 161-177 (2001).

24.K. Sherif, M. Thouin, and M. Mandviwalla, Extended Enterprise Applications and sustained competitive advantage, in: Proceedings of the 11th Americas Conference on Information Systems (AMCIS '05), August 11th - 14th 2005, Omaha, Nebraska, USA (Association for Information Systems, Atlanta, USA, 2005), pp. 2190-2194.

25.A. Tatnall, and A. Gilding, Actor-network theory and information systems research, in: Procedings of the 10th Australasian Conference on Information Systems (ACIS), Wellington, Victoria, New Zealand (University of Wellington, 1999), pp. 955-966.

26. R. Lamb, and R. Kling, R., Reconceptualising users as Social Actors in Information Systems Research, MIS Quarterly 27(2), 197-235 (2003). 
27.M.L. Nichols, A Behavioural Analysis for Planning MIS Implementation, MIS Quarterly March, 57-66 (1981).

28. J. Rose, Evaluating the Contribution of Structuration Theory to the Information System Discipline, in: Proceedings of the 6th European Conference on Information Systems (ECIS'98), Aix-en-Provence, France (Euro-Arab Management School, Granada, Spain, 1998). 29.H.Z. Klein, and M.D. Myers, A set of principles for conducting and evaluating Interpretive Field Studies in Information Systems, MIS Quarterly 23(1), 67-94 (1999).

30. J. Fiedler, Field Research: A Manual for Logistics and Management of Scientific Studies in Natural Settings (Jossey-Bass, San Francisco, USA, 1978).

31.F.B. Tan and M.G. Hunter, Using Narrative Inquiry In A Study Of Information Systems Professionals, in: Proceedings of the 36th Hawaii International Conference On System Science (HICSS'36), Hawaii, January 6-9 (IEEE Computer Society, New Jersey, 2003).

32.J.J. Shaughnessy and E.B. Zechmeister, Research methods in Psychology. Third edition, (McGraw Hill, New York, 1994).

33. D. Davis, State of a New Art: Manufacturing and Trading Partners Learn as they go, Manufacturing Systems 13(8), 2-10 (1995).

34.P.J. Dixon, and D.A. John, Technology Issues facing Corporate Management in the 1990s, MIS Quarterly, September 1989, 247-255 (1989).

35. E. Constantinides, Strategies for surviving the Internet meltdown: The case of two Internet incumbents, Management Decision 42(1), 89-107 (2004).

36. R.L. Kumar and C.W. Crook, A multi-disciplanary framework for the management of interorganisational systems, ACM SIGMIS Database 30(1), 22-37 (1999).

37.M.W. Chiasson and E. Davidson, Taking industry seriously in Information Systems Research. MIS Quarterly 29(4), 591-605 (2005).

38. G. Lin, M. Ettl, S. Buckley, S. Bagchi, D.S. Yao, B.L., Naccarato, R. Alan, K. Kim, and L. Koenig, Extended-Enterprise Supply-Chain Management at IBM Personal Systems Group and Other Divisions, Interfaces 30(1), 7-25 (2000). 